THEORY AND METHODS

\title{
Applying systematic review methods to studies of people's views: an example from public health research
}

\author{
Angela Harden, Jo Garcia, Sandy Oliver, Rebecca Rees, Jonathan Shepherd, Ginny Brunton, Ann \\ Oakley
}

J Epidemiol Community Health 2004;58:794-800. doi: 10.1136/jech.2003.014829

Methods for systematic reviews are well developed for trials, but not for non-experimental or qualitative research. This paper describes the methods developed for reviewing research on people's perspectives and experiences ("views" studies) alongside trials within a series of reviews on young people's mental health, physical activity, and healthy eating. Reports of views studies were difficult to locate; could not easily be classified as "qualitative" or "quantitative"; and often failed to meet seven basic methodological reporting standards used in a newly developed quality assessment tool. Synthesising views studies required the adaptation of qualitative analysis techniques. The benefits of bringing together views studies in a systematic way included gaining a greater breadth of perspectives and a deeper understanding of public health issues from the point of view of those targeted by interventions. A systematic approach also aided reflection on study methods that may distort, misrepresent, or fail to pick up people's views. This methodology is likely to create greater opportunities for people's own perspectives and experiences to inform policies to promote their health.

See end of article for authors' affiliations

Correspondence to: Ms A Harden, Social Science Research Unit, 18 Woburn Square, London WCIH ONS, UK a.harden@ioe.ac.uk

Accepted for publication 22 December 2003
$\mathrm{T}$ he context for this paper is using research to inform policy for promoting health, but the issues it raises-about systematic methods for bringing together studies that attempt to understand policy issues from the perspectives of the people they affect ("views" studies)-are important for health and social policy more generally.

Much energy goes into developing strategies for improving public services or tackling social issues. Not all such strategies take into account the experiences and views of those most closely concerned. ${ }^{2}$ There is an emerging consensus that good quality research about people's views should be used to inform policy alongside studies that describe the problem, investigate factors effects of interventions to tackle it. ${ }^{3}$ Attention to people's own perspectives is also advocated in disciplines such as sociology and anthropology. ${ }^{5}$ Research about people's views is often, but not always, "qualitative" in nature. As Oakley notes, it is considered by some to represent an alternative paradigm incompatible with the "quantitative" $^{\prime \prime}$ paradigm. ${ }^{6}$ that are associated with it, and evaluate the
Literature reviews accumulate learning and avoid the pitfalls of relying on single studies. Systematic reviews apply explicit methods to this task, such as comprehensive searching and the quality assessment of studies. There are therefore good reasons for applying systematic review methods to views studies. Systematic review methodology is well developed for trials, ${ }^{78}$ but the debate about systematic approaches to reviewing non-experimental research is in its early stages, ${ }^{910}$ with a small but growing body of methodological work on the synthesis of qualitative research. ${ }^{11-16}$ This paper aims to contribute to this debate by reflecting on methods used in a recent series of systematic reviews that included views studies alongside trials. The substantive findings have been reported elsewhere, ${ }^{17-19}$ as has a description of how the findings of views studies were integrated with the findings of trials. ${ }^{20}$

\section{DESCRIPTION OF REVIEW SERIES: APPROACH, PROCESSES, AND METHODS} Between 1999 and 2001 we carried out three systematic reviews on the barriers to, and facilitators of, mental health, physical activity, and healthy eating among young people, funded by the Department of Health (England).

Figure 1 illustrates our overall approach. We hypothesised that our review question "What is known about the barriers to, and facilitators of, health and health behaviour among young people?" could be answered by two types of study: (a) "intervention studies" to identify effective, ineffective, and harmful interventions; and (b) "non-intervention" studies that aimed to describe factors associated with mental health, physical activity, and healthy eating. A mapping exercise revealed a large number of primary studies $(\mathrm{n}=510)$. Meetings with project funders and other stakeholders identified subsets of studies for in depth review. For the "non-intervention" studies, a decision was made to focus on UK views studies, published in or after 1990.

The standard stages of a systematic review were used for the in depth review of views studies using specially developed tools. In the rest of this paper we reflect on how well this approach worked and the challenges that remain.

\section{Reflections on the approach}

(1) What is a "views" study

(a) Identifying "views" studies

We aimed to identify those studies that placed people's own voices at the centre of their 
REVIEW QUESTION

"What is known about the barriers to, and facilitators of, health and health behaviour among young people?"

\section{MAPPING EXERCISE}

1 Systematic and exhaustive searches identified 18686 citations

2 Retrieval, screening and classification of full reports of 510 primary studies (304

"intervention studies" and 206 "non-intervention" studies)

\section{CONSULTATION WITH KEY STAKEHOLDERS}

Focus for in depth review prioritised

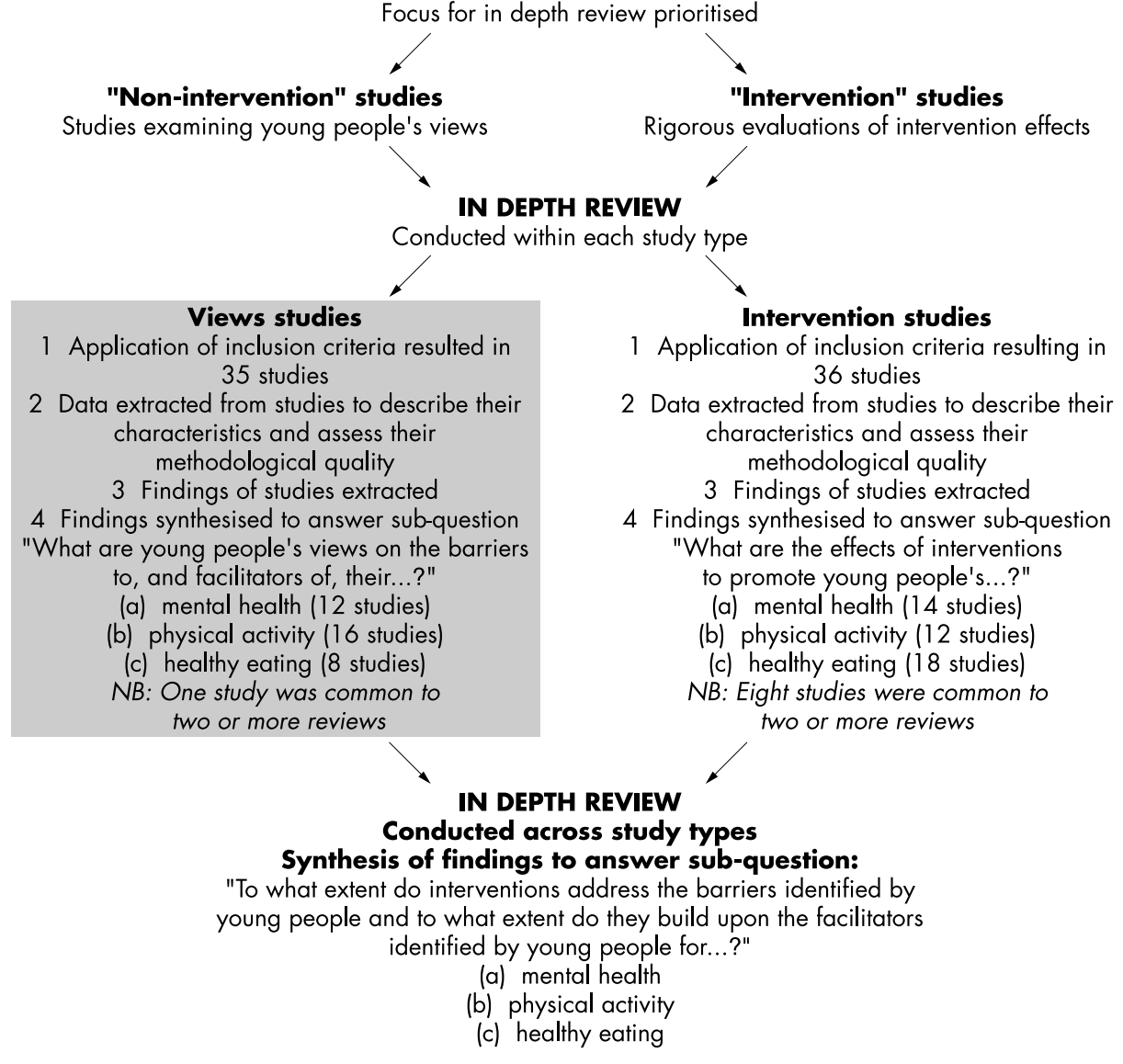

Figure 1 The review process (shaded area indicates main focus of this paper).

analysis. A total of 35 studies across the three reviews met this criterion. Some excluded studies did examine views, but used attitude scales and a statistical analysis to trace causal pathways to behaviours. These studies are amenable to meta-analysis.

Reports of views studies were not easy to find or access. On electronic databases we did not search specifically for views studies but combined topic keywords (for example, healthy eating) with population keywords (for example, young people). This meant that we had to sift through large numbers of citations (fig 1). A substantial number were grey literature reports $(n=12)$, identified by contacts with relevant organisations and authors.

(b) Methods used in "views" studies

Our 35 studies varied in the methods they used (table 1). It was not easy to classify studies according to whether they were "qualitative" or "quantitative". Some studies collected young people's views in their own words and then used frequencies to quantify them. Other studies that included both fixed response and open-ended items in questionnaires did not always report results from the latter.
(2) Can we trust the findings of "views" studies

(a) Quality criteria

For qualitative research there is fierce debate about what counts as good quality or whether quality should be a concern at all. ${ }^{21}$ This contrasts with the situation for trials where there is agreement that randomised comparison groups and concealment of outcome and/or allocation procedures are crucial $^{22}$ and validated instruments have been developed. ${ }^{23}$

We applied seven quality criteria that were common to sets of criteria proposed by four research groups for qualitative research (table 2). ${ }^{24-27}$

Quality assessment revealed that views studies fell significantly short of basic methodological standards (table 2). Only four of the 35 studies met all seven criteria (data not shown in table).

The quality assessment tool needs to be further developed. Two reviewers did not always agree on which criteria a study had met. Although reviewers always reached consensus after discussion, more detailed guidance on how to judge whether aspects of a study are "clear", "explicit", or "sufficient" is needed. 
Table 1 Methods of data collection and analysis used in studies of young people's views $(n=35)$

\begin{tabular}{lrr}
\hline & Number & $\%$ \\
\hline Methods of data collection & & \\
Fixed response self completion questionnaire & 9 & 26 \\
Fixed and open response self completion & 9 & 26 \\
questionnaire & & \\
Open response self completion questionnaire & 1 & 3 \\
Interviews and/or focus groups & 16 & 45 \\
Total & 35 & 100 \\
Methods of data analysis & 15 & 43 \\
Descriptive and/or inferential statistics & 16 & 45 \\
Qualitative data analysis & 4 & 12 \\
Combination & 35 & 100 \\
Total & & \\
\hline
\end{tabular}

(b) Using assessments of methodological quality

In systematic reviews of trials, quality assessment is used as a basis for excluding or weighting studies. Quality criteria for trials assess the extent to which their findings can be relied upon to answer questions about the effects of interventions. Choice of quality criteria is therefore driven by the review question.

We did not exclude or weight views studies because there is no consensus about the "right" way to assess the quality of views studies. In our reviews, we were piloting one of many possible sets of criteria. On reflection, we found that their main strength was providing an explicit framework for highlighting the strengths and weaknesses of studies. However, they focused mainly on generic issues of reporting quality, which did not help us to assess studies in relation to our review question-understanding what young people see as the barriers to, and facilitators of, their health behaviour. In future reviews, additional quality criteria are required to assess whether study findings are rooted in young people's own perspectives.

Our experiences with the 35 views studies highlighted three issues for additional criteria to cover:

- Pilot work before finalising data collection tools to ensure that questions and/or response categories are meaningful to young people. Pilot work appeared to be the exception rather than the rule among the views studies $(n=14)$, and this raises questions about whether findings reflected researchers' a priori assumptions rather than young people's own views.

- Methods of data analysis. Detail on such methods was rarely given in views studies (see table 2) and it was difficult to tell whether themes were grounded in young people's views. In some studies pre-defined coding

Table 2 Number and percentage of studies of young people's views $(n=35)$ meeting each quality criterion

\begin{tabular}{lll}
\hline Criteria & Number & $\%$ \\
\hline 1 An explicit theoretical framework & 16 & 46 \\
and/or literature review & 32 & 91 \\
2 Aims and objectives clearly stated & 31 & 88 \\
3 A clear description of context & 17 & 49 \\
4 A clear description of the sample and & & \\
how it was recruited. & 22 & 63 \\
5 A clear description of methods used to & 6 & 17 \\
collect and analyse data. & & \\
$\begin{array}{l}\text { 6 Attempts made to establish the reliability } \\
\text { or validity of data analysis }\end{array}$ & 61 & 60 \\
7 Inclusion of sufficient original data to & 21 \\
mediate between evidence and interpretation & & \\
\hline
\end{tabular}

strategies, often derived from interview or focus group schedules, were used to analyse data.

- Ensuring the full and active participation of young people in the research. Few studies reported attempts to ensure confidentiality $(n=12)$ or consent procedures $(n=7)$. When these features were absent, findings may have only represented what young people were prepared to admit in a potentially uncomfortable research situation.

Attention to these shortcomings and their potential to distort, misrepresent, or simply fail to pick up the views of young people is a key challenge for future qualitative and quantitative views studies. It would be unwise for future systematic reviews of these types of studies to include poor quality studies; this would represent a "double standard" in comparison with systematic reviews of trials.

(3) How can the findings of "views" studies be synthesised

(a) Rendering "views" studies comparable

With the advent of the CONSORT and STARD statements, ${ }^{28} 29$ trial and diagnostic study reports are more likely to be presented in a standard way. Reports of views studies varied in writing styles and publication formats. Our data extraction tool was essential in helping to "deconstruct" each study. We were then able to "reconstruct" the studies in a standard format, using "evidence" tables (see tables 3 and 4) and structured summaries, to facilitate comparison between them. Two types of evidence tables were prepared and these are illustrated in tables 3 and 4 . Structured summaries were between one and two pages in length, elaborating on, and putting into context, the information presented in the evidence tables.

Two researchers reconstructing studies in a standard format meant that at least two members of the review team had in depth knowledge of each study. This was labour intensive but crucial to the success of the synthesis.

The synthesis process was non-linear and involved reviewers going back and forth between the original papers, their data extractions, and the "evidence" tables. We found it useful to draw on the metaphors normally associated with qualitative analysis to describe the process. For example, by rendering the views studies comparable we had "immersed ourselves in the data" as we constructed the synthesis.

\section{(b) Using qualitative analysis techniques for synthesis}

In statistical meta-analysis, the way effect sizes are synthesised can be captured by the term "pooling". Pooling effect sizes is akin to creating one large study to answer a review question. For it to be appropriate to pool findings using statistical meta-analysis, studies must be as similar as possible in the question they try to answer and the methods they use to answer it. Differences in questions and methods used in the views studies meant that their findings were not suitable for pooling in this sense. In our reviews, "aggregating" findings across studies rather than "pooling" was a more useful metaphor for describing synthesis, whereby findings are broken down, interrogated, and then combined into a whole via a listing of themes. ${ }^{31}$ The methods for synthesis developed iteratively across the three reviews in the series. We worked by using both a priori codes to group studies as well as allowing themes to emerge. There were three main steps:

Step 1: Classifying studies

We classified studies assessing similar aspects of young people's views. We asked how the findings of the "views" studies could contribute to informing intervention development. Four main issues emerged from the studies included in the mental health review and these areas were subsequently specified a priori in the physical activity and healthy eating 
Table 3 Aims, sample characteristics, and findings of studies of young people's views about physical activity: an illustration taken from the evidence tables

\begin{tabular}{|c|c|c|c|c|}
\hline Study & Aims & Sample characteristics & Key findings reported by authors & $\begin{array}{l}\text { Young people's views (judged by } \\
\text { reviewers) }\end{array}$ \\
\hline \multirow[t]{6}{*}{$\begin{array}{l}\text { Sports Council } \\
\text { Wales }(1994)^{30}\end{array}$} & \multirow{6}{*}{$\begin{array}{l}\text { To examine young } \\
\text { people's feelings and } \\
\text { attitudes about sport } \\
\text { To explore the } \\
\text { meanings of sports for } \\
\text { young people and how } \\
\text { they view their own } \\
\text { involvement and the } \\
\text { involvement of others }\end{array}$} & $\begin{array}{l}\text { Location: Wales (Pontypool, } \\
\text { Haverfordwest, Wrexham, } \\
\text { Swansea, and Maesteg) }\end{array}$ & $\begin{array}{l}\text { - Young people tend to operate with a } \\
\text { restricted definition of the word "sport" } \\
\text { where it is taken to mean organised, rule } \\
\text { governed, and competitive activity }\end{array}$ & $\begin{array}{l}\text { Perceptions of/meanings of physical } \\
\text { activity }\end{array}$ \\
\hline & & Sample number: 60 & $\begin{array}{l}\text { Pleasures associated with sport differ } \\
\text { depending on degree to which it is } \\
\text { perceived as recreational-work ethic } \\
\text { prevalent. }\end{array}$ & $\begin{array}{l}\text { Distinction between organised, } \\
\text { competitive "real" sport and } \\
\text { "recreational sport for leisure". }\end{array}$ \\
\hline & & Age range: $11-16$ & $\begin{array}{l}\text { Egalitarian views widespread among } \\
\text { young people as regards own and } \\
\text { peers' participation but tendency to } \\
\text { revert to gender stereotypes when } \\
\text { discussing adult participation. }\end{array}$ & Barriers \\
\hline & & Sex: mixed & $\begin{array}{l}\text { - Body image important for participation, } \\
\text { especially for young women. }\end{array}$ & $\begin{array}{l}\text { - PE teachers' favouritism of young } \\
\text { people who do well at sport. }\end{array}$ \\
\hline & & $\begin{array}{l}\text { Social class: not stated } \\
\text { Ethnicity: all described as "white". } \\
\text { A minority were Welsh speaking. } \\
\text { Other information: sample over } \\
\text { represented young women and } \\
\text { aimed to include those less } \\
\text { committed to sport. }\end{array}$ & & $\begin{array}{l}\text { Young women's concern over their } \\
\text { physical appearance. } \\
\text { Bad weather a problem for team } \\
\text { games. } \\
\text { Facilitators }\end{array}$ \\
\hline & & Exclusions: none reported. & & $\begin{array}{l}\text { - More encouragement at sports clubs } \\
\text { for "non-sporty" people. } \\
\text { - Making sport more fun } \\
\text { - Provision of more opportunities to } \\
\text { compete for young women. }\end{array}$ \\
\hline
\end{tabular}

reviews: (a) what the terms mental health, physical activity, and healthy eating meant to young people; (b) what stopped young people from being physically active or eating healthily or what made young people feel bad; (c) what helped young people to be physically active, eat healthily, or feel good; and (d) young people's own ideas about how to promote their mental health, physical activity, or healthy eating.

Step 2: Comparing and contrasting findings

We compared and contrasted findings across studies to identify similarities and differences. For example, in the mental health review, 10 of the included studies examined sources of stress or worry for young people. The most common ones were: school work; physical appearance; choosing and finding a job; lack of material resources; feeling powerless; relationships with friends and wider peer groups; and family discord. When we identified differences in findings, we examined whether these could be explained by the differences in methods or sample characteristics. For example, in the mental health review, differences in preferred coping strategies were explored by age and sex. Young women reported talking to friends or trusted adults as their usual coping strategies, and older young people reported using drugs, alcohol, or physical aggression. In this way we were able to describe the range of views held by young people and highlight those which may be more important for particular groups of young people.

Table 4 Methodological characteristics and quality of studies of young people's views about physical activity: an illustration taken from the evidence tables

\begin{tabular}{|c|c|c|c|c|c|}
\hline Study & $\begin{array}{l}\text { Sampling methods } \\
\text { (identification; selection; } \\
\text { recruitment) }\end{array}$ & $\begin{array}{l}\text { Data collection instrument; } \\
\text { setting; (reliability/validity) }\end{array}$ & $\begin{array}{l}\text { Data analysis(approach; } \\
\text { reliability/validity) }\end{array}$ & ; Quality & $\begin{array}{l}\text { Participation(in } \\
\text { research process, } \\
\text { consent) }\end{array}$ \\
\hline \multirow[t]{2}{*}{$\begin{array}{l}\text { Sports Council } \\
\text { Wales }(1994)^{30}\end{array}$} & $\begin{array}{l}\text { Young people taking part in } \\
\text { larger questionnaire study } \\
\text { invited to be interviewed. }\end{array}$ & $\begin{array}{l}\text { - In depth interviews } \\
\text { conducted by research } \\
\text { team in participants' homes, } \\
\text { sometimes with parents } \\
\text { present; no detail reported } \\
\text { on questions asked or themes } \\
\text { explored. }\end{array}$ & $\begin{array}{l}\text { - Unclear-direct } \\
\text { quotations were } \\
\text { grouped under } \\
\text { thematic headings }\end{array}$ & $\begin{array}{l}\text { Met five of the seven } \\
\text { criteria listed in } \\
\text { table } 2 \text {. Did not } \\
\text { provide a clear } \\
\text { description of data } \\
\text { collection and analysis } \\
\text { methods; there were } \\
\text { no attempts to establish } \\
\text { the reliability or } \\
\text { validity of data analysis. }\end{array}$ & $\begin{array}{l}\text { - Unclear whether } \\
\text { consent was } \\
\text { obtained for } \\
\text { interviews. }\end{array}$ \\
\hline & $\begin{array}{l}\text { - Further participants recruited } \\
\text { via "snowball sample" to } \\
\text { identify those less committed } \\
\text { to sport. }\end{array}$ & $\begin{array}{l}\text { Interviewers had considerable } \\
\text { experience of working with } \\
\text { young people }\end{array}$ & & & $\begin{array}{l}\text { Interviews were } \\
\text { tape recorded with } \\
\text { participants' } \\
\text { permission. } \\
\text { No mention of } \\
\text { issues of } \\
\text { confidentiality. }\end{array}$ \\
\hline
\end{tabular}




\section{Key points}

- We have developed, and propose for wider use, methods for including non-experimental and "qualitative" research examining people's perspectives and experiences of health and social issues ("views" studies) in systematic reviews.

- Bringing together the findings of quantitative and qualitative views studies in a systematic way can be achieved through the application of conventional systematic review principles and methods (for example, reducing bias, exhaustive searching) supplemented with more novel ones (for example, increasing breadth and depth of understanding as well as reducing bias, qualitative synthesis techniques).

- Further research is needed to examine the value of this approach by comparing it with non-systematic reviews with a similar scope. An additional challenge is to examine the impact on the conclusions of a review of including and excluding studies of different methodological quality.

\section{Step 3: Thematic analysis}

To answer our over-arching review question about barriers and facilitators we aimed to integrate the findings of the views study synthesis with those from trials of interventions in the three topic areas. Our methods for integrating these are reported elsewhere. ${ }^{20}$ However, our views studies were the starting point for this integration and to prepare for this we used thematic analysis to identify and group barriers and facilitators. At first, we drew on contemporary models of health promotion that suggested interventions should target barriers and facilitators at the individual, community, and society level. ${ }^{32}{ }^{33}$ We struggled to understand the findings of our views studies using these categories. We found that young people talked about what helped and what hindered their health and behaviour within four inter-related "realms" covering: the school; family and friends; the self; and practical and material resources. These emergent categories, which re-aligned the categories suggested by theory to more closely match the issues raised by young people, were used to classify barriers and facilitators (table 5).

\section{(4) Is it worth it?}

Reducing the potential for bias is a key strength of systematic reviews. ${ }^{4834}$ We identified two other strengths of a systematic approach to reviewing research: greater breadth and greater depth.

In terms of breadth, a large number of young people from diverse groups were able to contribute their views. A total of 37335 young people were accessed across the studies (based on the 33 studies that reported a sample number). We paid particular attention to the characteristics of study samples on key markers of inequalities. Attention to issues of gender across the studies was fairly comprehensive; five studies focused on the views of young men or young women alone, and a further 17 studies looked for differences in views between these two groups (table 6). However, our reviews were limited in their ability to examine how young people's views were related to their social class and ethnic background because of the scant information provided; 24 of the 35 studies did not report this information. Our reviews were able to highlight these gaps and recommend that primary research be commissioned to address this. The analysis offered a clear message to researchers to describe the social characteristics of their samples more carefully. Of the 37335 young people included in the studies, the social class of 36437 or $98 \%$ of them was not reported (the same figures for ethnicity were 33813 or $91 \%)$.

Our included studies varied in terms of the depth of their descriptions and analysis. For example, some studies highlighted the range of things that young people identified as

Table 5 Examples of the barriers and facilitators derived from studies of young people's views $(n=35)$

\begin{tabular}{|c|c|c|c|}
\hline Spheres of influence & Mental health & Physical activity & Healthy eating \\
\hline \multirow[t]{6}{*}{ Self } & Barriers & Barriers & Barriers \\
\hline & Feeling powerless & Lack of confidence in skills & Taste preferences for 'fast foods' \\
\hline & Worries about personal appearance & Preference for other activities & $\begin{array}{l}\text { Concern over appearance can lead to } \\
\text { dieting }\end{array}$ \\
\hline & Facilitators & Facilitators & $\begin{array}{l}\text { diefıng } \\
\text { Facilitators }\end{array}$ \\
\hline & Indulging in pleasurable activities & Opportunity to show off skills & "Will power" \\
\hline & Being creative & Help with weight loss & \\
\hline \multirow[t]{5}{*}{ Family and friends } & Barriers & Barriers & Barriers \\
\hline & $\begin{array}{l}\text { Being excluded by peers/ bullying } \\
\text { Concern that worries will not be } \\
\text { underplayed by adults }\end{array}$ & $\begin{array}{l}\text { Parental constraint on walking to school } \\
\text { Fear of negative evaluation by peers }\end{array}$ & $\begin{array}{l}\text { Snacks and fast food eaten within social } \\
\text { spaces outside the home }\end{array}$ \\
\hline & Facilitators & Facilitators & Facilitators \\
\hline & Talking to friends for stress; adults for & Social aspects of taking part & Healthy food associated with the home and \\
\hline & $\begin{array}{l}\text { unfamiliar or serious problems } \\
\text { Being listened to and respected }\end{array}$ & $\begin{array}{l}\text { Combining sports and leisure facilities to } \\
\text { increase opportunities for socialising }\end{array}$ & adulthood. \\
\hline \multirow[t]{5}{*}{ The school } & Barriers & Barriers & Barriers \\
\hline & $\begin{array}{l}\text { Heavy workload and exams eating into } \\
\text { free time }\end{array}$ & $\begin{array}{l}\text { Negative experiences of PE at school (for } \\
\text { example, attitudes of teachers) }\end{array}$ & Lack of healthy choices in school canteen \\
\hline & Boredom and monotony of school & Lack of facilities at school & \\
\hline & Facilitators & Facilitators & Facilitators \\
\hline & Achieving in school & Consultation in choice of activities at school & Provision of information about the \\
\hline \multirow{5}{*}{$\begin{array}{l}\text { Practical and } \\
\text { material resources }\end{array}$} & Barriers & Barriers & Barriers \\
\hline & $\begin{array}{l}\text { Worry about choosing and finding a job } \\
\text { Having nothing to do }\end{array}$ & $\begin{array}{l}\text { Lack of money and time } \\
\text { Structured physical activity associated with } \\
\text { childhood not adulthood }\end{array}$ & $\begin{array}{l}\text { "Fast food" is cheap and easy to access } \\
\text { "Healthy food" is expensive and difficult to } \\
\text { access }\end{array}$ \\
\hline & Facilitators & Facilitators & Facilitators \\
\hline & Money and financial security & Create more cycle lanes & $\begin{array}{l}\text { Provide healthier snacks in vending } \\
\text { machines }\end{array}$ \\
\hline & Physical activity & Increasing access to clubs for dancing & Reduce cost of healthier snacks \\
\hline
\end{tabular}


Table 6 Number of studies of young people's views $(n=35)$ according to their focus on gender; social class; and ethnicity

\begin{tabular}{|c|c|c|c|c|c|}
\hline Gender & Number & Social class & Number & Ethnicity & Number \\
\hline $\begin{array}{l}\text { Focused solely on } \\
\text { young women }\end{array}$ & 4 & $\begin{array}{l}\text { Focused solely on } \\
\text { working class }\end{array}$ & 3 & $\begin{array}{l}\text { Focused solely on ethnic } \\
\text { minority groups }\end{array}$ & 1 \\
\hline $\begin{array}{l}\text { Focused solely on } \\
\text { young men }\end{array}$ & 1 & $\begin{array}{l}\text { Focused solely on } \\
\text { middle class }\end{array}$ & 1 & $\begin{array}{l}\text { Ethnic minority groups } \\
\text { not represented }\end{array}$ & 2 \\
\hline $\begin{array}{l}\text { No specific focus, } \\
\text { but gender used in } \\
\text { analysis }\end{array}$ & 17 & $\begin{array}{l}\text { No specific focus, but } \\
\text { social class used in analysis }\end{array}$ & 2 & $\begin{array}{l}\text { No specific focus, but } \\
\text { ethnicity used in analysis }\end{array}$ & 0 \\
\hline $\begin{array}{l}\text { Gender of sample } \\
\text { reported, but not } \\
\text { used in analysis }\end{array}$ & 13 & $\begin{array}{l}\text { Social class of sample } \\
\text { reported, but not used } \\
\text { in analysis }\end{array}$ & 5 & $\begin{array}{l}\text { Ethnicity of sample } \\
\text { reported, but not used in } \\
\text { analysis }\end{array}$ & 8 \\
\hline Gender not reported & 0 & Social class not reported & 24 & Ethnicity not reported & 24 \\
\hline
\end{tabular}

\section{Policy implications}

- The contribution that non-experimental and qualitative research can make to evidence informed policy and practice has been limited in the past because of uncertainty about how to include it in systematic reviews.

- Advances made in systematic review methods for these study types in a recent review series has created a unique opportunity for young people's own perspectives and experiences to inform the development, implementation, and evaluation of interventions to promote their health.

barriers and facilitators, others identified the relative importance of different barriers and facilitators for different groups of young people, and some examined why or how different factors acted as barriers and facilitators. For example, in the physical activity review, consistent differences between young men and young women were found across the 16 included "views" studies, with young women reporting lower participation rates and less favourable attitudes. However, insight into why this might be the case was only addressed in four studies.

Although it seems that issues of breadth are likely to be tackled by quantitative studies and issues of depth by qualitative studies, this was not always the case. Greater breadth was often provided by both smaller scale qualitative studies focusing on particular groups of young people and by large scale quantitative studies focusing on a range of different groups. Greater depth was not always provided by qualitative studies. Some studies of this type described the range of views held, but did not analyse these views further.

\section{CONCLUSIONS AND FUTURE DIRECTIONS}

Through a series of reviews in the area of health promotion for young people, we have developed methods for including in systematic reviews non-experimental and "qualitative" research examining people's perspectives and experiences. We combined conventional systematic review principles and methods with more novel ones developed in the course of the review series. Using the techniques and terminology usually associated with qualitative analysis of primary research data helped us to be systematic and explicit. In addition to the goal of reducing bias, considerations of depth and breadth seem to be at the heart of producing good quality and useful syntheses of views studies. The specific methods for synthesis we developed in our review series have much in common with those recently developed and applied in the substantive areas of nursing and illness experiences. ${ }^{13}$ 35-37 This work has emphasised the theory building potential of synthesis. Our work also makes use of this potential by using young people's views and experiences to generate theories about which interventions might work to promote their health. The work reported in this paper extends this new genre of syntheses of qualitative research into public health, setting it explicitly within a systematic review framework.

It would be fruitful to test out the methods developed here in other reviews. One question is whether adopting a systematic approach produces different findings from nonsystematic reviews. Work is also needed on assessing the quality of views studies. Our experience suggests that we need to move beyond generic criteria about the quality of reporting of methods to assess the extent to which study findings are rooted in people's own perspectives and experiences. We have suggested three possible issues to consider in the development of such criteria (pilot work for data collection tools; careful use of pre-defined coding schemes for data analysis; and active participation of people in research). Such criteria would need to be empirically tested, alongside the criteria suggested by other groups, ${ }^{58}$ by asking what happens to the conclusions of reviews if we exclude studies that "fail" different sets of quality criteria. The usefulness of any systematic review depends on the quality of studies available. Our review series exposed some serious shortcomings of young people's views studies and we hope that more reviews of this type will improve the way that these types of studies are designed, implemented, and reported.

\section{ACKNOWLEDGEMENTS}

The work reported in this paper is part of a programme of work on advancing evidence based health promotion at the EPPI-Centre funded by the Department of Health (England). The views expressed are those of the authors and not necessarily those of the Department of Health.

\section{Authors' affiliations}

A Harden, J Garcia, S Oliver, R Rees, J Shepherd, G Brunton, A Oakley, Evidence for Policy and Practice Information and Co-ordinating Centre (EPPI-Centre), Social Science Research Unit, Institute of Education, University of London, UK

Conflicts of interest: none declared.

\section{REFERENCES}

1 Harden A, Oliver S. Who's listening? Systematically reviewing for ethics and empowerment. In: Oliver S, Peersman G, eds. Using research for effective health promotion. Buckingham: Open University Press, 2001:123-37.

2 Mullender A, Hague G. Women survivors' views. In: Taylor-Browne J, ed. What works in reducing domestic violence? London: Whiting and Birch, 2001:1-33.

3 Department of Health. Patient and public involvement in the new NHS. London: HMSO, 1999. 
4 Oliver S, Peersman G. Using research for effective health promotion. Buckingham: Open University Press, 2001:200

5 Popay J, Rogers A, Williams G. Rationale and standards for the systematic review of qualitative literature in health services research. Qualitative Health Research 1998:8:341-51.

6 Oakley A. Experiments in knowing: gender and methods in the social sciences. Cambridge: Polity Press, 2000.

7 Cooper H, Hedges L. The handbook of research synthesis. New York: Russell Sage Foundation, 1994

8 Egger G, Davey Smith G, Altman D. Systematic reviews in health care: metaanalysis in context. London: BMJ Books, 2001

9 Dixon-Woods M, Fitzpatrick R, Roberts K. Including qualitative research in systematic reviews: opportunities and problems. J Eval Clin Pract 2001;7:125-33.

10 Nixon J, Khan K, Kleiinen J. Summarising economic evaluations in systematic reviews: a new approach. BMJ $2001 ; 322$ :1596-8.

11 Jensen L, Allen M. Meta-synthesis of qualitative findings. Qualitative Health Research 1996;6:553-60.

12 Kearney M. Enduring love: a grounded formal theory of women's experience of domestic violence. Res Nurs Health $2001 ; 24: 270-82$.

13 McNaughton D. A synthesis of qualitative home visiting research. Public Health Nurs 2000; 17:405-14.

14 Noblit G, Hare R. Meta-ethnography: synthesising qualitative studies. Newbury Park, CA: Sage, 1988.

15 Patterson B, Thorne S, Canam C, et al. Meta-study of qualitative health research. Thousand Oaks, CA: Sage, 2001

16 Schreiber R, Crooks D, Stern P. Qualitative meta-analysis. In: Morse J, ed. Completing a qualitative project: details and dialogue. Thousand Oaks, CA Sage, 1997:311-27

17 Harden A, Rees R, Shepherd J, et al. Young people and mental health: a systematic review of barriers and facilitators. London: EPPI-Centre Social Science Research Unit, 2001

18 Rees R, Harden A, Shepherd J, et al. Young people and physical activity: a systematic review of barriers and facilitators. London: EPPI-Centre, Social Science Research Unit, 2001

19 Shepherd J, Harden A, Rees R, et al. Young people and healthy eating: a systematic review of barriers and facilitators. London: EPPI-Centre, Social Science Research Unit, 2001.

20 Oliver S, Harden A, Rees R, et al. An emerging framework for including different types of evidence in systematic reviews for public policy. Evaluation (in press).
21 Lincoln Y. Emerging criteria for quality in qualitative and interpretive research. Qualitative Inquiry 1995; 1:275-89.

22 Juni $P$, Altman D, Egger M. Assessing the quality of controlled clinical trials. BMJ 2001;323:42-6.

23 Moher D, Cook DJ, Jadad A, et al. Assessing the quality of reports of randomised trials: implications for the conduct of meta-analyses. Health Technol Assess 1999;3:1-55

24 Boulton M, Fitzpatrick R, Swinburn C. Qualitative research in health care II: a structured review and evaluation of studies. J Eval Clin Pract 1996;2:171-9.

25 Cobb AK, Hagemaster JN. Ten criteria for evaluating qualitative research proposals. J Nurs Edu 1987;26:138-43.

26 Mays N, Pope C. Rigour and qualitative research. BMJ 1995;311:109-12.

27 Blaxter M. Criteria for the evaluation of qualitative research papers. Medical Sociology News 1996;22:69-71.

28 Begg C, Cho M, Eastwood S, et al. Improving the quality of reporting of randomized controlled trials: the CONSORT statement. JAMA 1996;276:637-9.

29 Bossuyt P, Reitsma J, Bruns D, et al. Towards complete and accurate reporting of studies of diagnostic accuracy: the STARD initiative. BMJ 2003;326:41-4.

30 Sports Council for Wales. A matter of fun and games: children's participation in sport. Cardiff: Sports Council for Wales, 1994.

31 Estabrooks C, Field P, Morse J. Aggregating qualitative findings: an approach to theory development. Qualitative Health Research 1994;4:503-1 1.

32 Hawe $\mathbf{P}$, Degeling D, Hall J. Evaluating health promotion. Sydney: MacLennan and Petty, 1990.

33 Green L, Kreuter M. Health promotion planning: an educational and environmental approach. Mountain View, CA: Mayfield, 1991.

34 Maynard I, Chalmers I. Non-random reflections on health services research. London: BMJ Books, 1997.

35 Barroso J, Powell-Cope G. Metasynthesis of qualitative research on living with HIV infection. Qualitative Health Research 2000;10:340-53.

36 Campbell R, Pound P, Pope C, et al. Evaluating meta-ethnography: a synthesis of qualitative research on lay experiences of diabetes and diabetes care. Soc Sci Med 2003;56:671-84.

37 Paterson B. The shiffing perspectives model of chronic illness. Journal of Nursing Scholarship 2001 ;33:57-62.

38 Spencer L, Richie J, Lewis J, et al. Quality in qualitative evaluation: a framework for assessing research. London: Government Chief Social Researcher's Office, 2003. 